\title{
Rejection of adenovirus infection is independent of coxsackie and adenovirus receptor expression in cisplatin-resistant human lung cancer cells
}

\author{
NIAN-HUA ZHANG ${ }^{1-3}$, RUI-QING PENG ${ }^{2,3}$, YA DING $^{2,3}$ and XIAO-SHI ZHANG ${ }^{2,3}$ \\ ${ }^{1}$ Department of Oncology, Guangdong Second Provincial Traditional Chinese Medicine Hospital, Guangzhou, \\ Guangdong 510095; ${ }^{2}$ State Key Laboratory of Oncology in South China, and ${ }^{3}$ Melanoma Unit and Biotherapy Center, \\ Sun Yat-sen University Cancer Center, Guangzhou, Guangdong 510060, P.R. China
}

Received December 26, 2015; Accepted February 6, 2016

DOI: $10.3892 /$ or.2016.4870

\begin{abstract}
The adenovirus vector-based cancer gene therapy is controversial. Low transduction efficacy is believed to be one of the main barriers for the decreased expression of coxsackie and adenovirus receptor (CAR) on tumor cells. However, the expression of CAR on primary tumor tissue and tumor tissue survived from treatment has still been not extensively studied. The present study analyzed the adenovirus infection rates and CAR expression in human lung adenocarcinoma cell line A549 and its cisplatin-resistant subline A549/DDP. The results showed that although the CAR expression in A549 and A549/DDP was not different, compared with the A549, A549/DDP appeared obviously to reject adenovirus infection. Moreover, we modified CAR expression in the two cell lines with proteasome inhibitor MG-132 and histone deacetylase inhibitor trichostatin A (TSA), and analyzed the adenovirus infection rates after modifying agent treatments. Both TSA and MG-132 pretreatments could increase the CAR expression in the two cell lines, but the drug pretreatments could only make A549 cells more susceptible to adenovirus infectivity.
\end{abstract}

\section{Introduction}

Non-small cell lung cancer (NSCLC) is one of the most common cancers in many countries, and treatment outcomes for NSCLC patients are still disappointing. Most patients receiving chemotherapy do not respond, resulting in disease progression. Thus, inherent or acquired drug-resistance leads

Correspondence to: Dr Xiao-Shi Zhang, Melanoma Unit and Biotherapy Center, Sun Yat-sen University Cancer Center, Guangzhou, Guangdong 510060, P.R. China

E-mail: zhangxsh@sysucc.org.cn

Abbreviations: CAR, coxsackie and adenovirus receptor; rAd.EGFP, recombinant adenovirus encoding enhanced green fluorescent protein; MOI, multiplicities of infection

Key words: cisplatin-resistant, adenovirus infection rejection, coxackie and adenovirus receptor, lung cancer to treatment failure. In recent years, progress in chemotherapy and molecular target-based therapy have altered the standard therapy for NSCLC (1-3). Gene therapy has become an attractive regimen, in addition to conventional therapy (4). Adenovirus is a useful agent for cancer gene therapy due to its high potential for gene transfer, ease of high titer production and demonstrated safety in clinical trials (5). Thus, recombinant adenovirus vectors are widely used in preclinical and clinical gene therapy, particularly in NSCLC gene therapy (6). Moreover, results have suggested synergism between chemotherapy and adenovirus p53 gene therapy with no increased side effects (7). However, in a multicenter phase II study, intratumoral adenoviral p53 gene therapy appears to provide no additional benefit in patients receiving an effective first line chemotherapy for advanced NSCLC (8).

The combination of adenovirus with its receptor is a key step for virus infection and sequent biological effect. Adenovirus can infect cells since it uses the knob domain of the fiber binding to its cellular receptor, the coxsackie and adenovirus receptor (9). Several lines of evidence showed the relationships between CAR expression and adenovirus infection $(10,11)$, and low levels of CAR in tumors are thought to be one of the reasons for poor adenovirus infection (12-14). It has become evident that CAR expression is often low in various types of tumors, and some biological or chemical agents could result in an increase in CAR expression in several tumor cell lines, making them more susceptible to adenovirus infectivity (15-17).

Adenoviral vector-mediated gene transfer is highly effective, but large differences regarding transduction efficiencies among different cell lines and between in vitro and in vivo gene transfer have been reported. To evaluate the potential of adenovirus vector-based gene therapy on cisplatin-resistant lung cancer, the present study examined the adenovirus infection rates and CAR expressions in A549 and its cisplatinresistant subline A549/DDP.

\section{Materials and methods}

Cells culture, antibodies and chemicals. The human lung adenocarcinoma cell lines A549 and its cisplatin-resistant 
subline A549/DDP, were propagated in monolayer cultures in RPMI-1640 medium supplemented with $10 \%$ fetal bovine serum (FBS), $100 \mathrm{U} / \mathrm{ml}$ penicillin and $100 \mathrm{mg} / \mathrm{ml}$ streptomycin. The transformed embryonic kidney cell line 293 was grown in Dulbecco's modified Eagle's medium (DMEM) containing high glucose $(4.5 \mathrm{~g} / \mathrm{l}), 10 \% \mathrm{FBS}, 100 \mathrm{U} / \mathrm{ml}$ penicillin and $100 \mathrm{mg} / \mathrm{ml}$ streptomycin. Cells were grown at $37^{\circ} \mathrm{C}$ in a $5 \% \mathrm{CO}_{2}$ humidified incubator. Antibodies were commercially available, including mouse monoclonal antibody against CAR (Upstate Biotechnology, Charlottesville, VA, USA), rabbit polyclonal antibody against CAR, mouse monoclonal antibody against p53, mouse monoclonal antibody against p21, mouse monoclonal antibody against $\alpha$-tubulin and mouse monoclonal antibody conjugated with HRP against actin (Santa Cruz Biotechnology, Santa Cruz, CA, USA). Histone deacetylase inhibitor trichostatin A (TSA) and proteasome inhibitor MG-132 was purchased from Sigma Chemicals (St. Louis, MO, USA). Each agent was prepared as a stock solution in dimethyl sulphoxide (DMSO) medium such that the final concentration of DMSO exposed to cells was $<0.1 \%$. In all experiments, control cells were treated with $0.1 \%$ DMSO. Each experiment was repeated at least three times.

MTT assay. Cells were plated into 96-well tissue culture plates overnight. Then, cells were treated with cisplatin, MG-132 or TSA at the indicated concentrations, respectively, for $72 \mathrm{~h}$. Four hours before the end point, a medium containing $0.5 \mathrm{mg} / \mathrm{ml}$ MTT was added. Finally DMSO was added to each well and mixed thoroughly to dissolve the crystals of MTT formazan. Results were quantified using a LabSystems Multiskan MS at $540 \mathrm{~nm}$ wavelength. Control absorbance was designated as $100 \%$, and cell survival was expressed as a percentage of control absorbance.

FACS assay. The effect of MG-132 and TSA on CAR or GFP expression in cell lines was examined with FACS (Becton-Dickinson, Franklin Lakes, NJ, USA). Cells were incubated with MG-132 or TSA for the indicated hours. Before analysis, cells were washed, trypsinized and resuspended in phosphate-buffered saline (PBS). Cells $\left(2 \times 10^{5}\right)$ were incubated with antibody against CAR at a 1:200 dilution for $1 \mathrm{~h}$ at $4^{\circ} \mathrm{C}$, followed by FITC-labeled goat anti-mouse IgG for $30 \mathrm{~min}$ at $4^{\circ} \mathrm{C}$. After fixation, $3 \times 10^{4}$ cells were analyzed by FACS. Analysis was performed using LYSYS II software (Becton-Dickinson). To analyze the GFP expression, cells were trypsinized, washed and fixed for analysis.

Transfer assay. Recombinant adenovirus encoding enhanced green fluorescent protein (rAd.EGFP) was purchased from Sino-Gene (Shanghai, China). The cytomegalovirus promoter was used to drive the transcription of EGFP. Titers of recombinant viruses were determined by plaque forming assay in the 293 cells. All vectors were prepared, purified and stored at $-80^{\circ} \mathrm{C}$.

The rAd.EGFP transfer assay for the potential of adenovirus transfer detected with a fluorescence microscope and FACS. Cells $\left(5 \times 10^{4}\right)$ were plated into 24 -well plates overnight at $37^{\circ} \mathrm{C}$. Next day, fresh medium or fresh medium containing MG-132 or TSA cells were replaced. Twenty-four hours later, medium was removed and cells were washed once with PBS.
Then, cells were infected with rAd.EGFP at indicated MOI for $2 \mathrm{~h}$. Subsequently, cells were washed and overlaid with growth medium for the indicated time periods.

For fluorescence microscope analysis, a Leica fluorescence stereo microscope equipped with a $50 \mathrm{~W}$ mercury lamp was used. Selective excitation of GFP was produced through a D425/60 bandpass filter. Emitted fluorescence was collected through a long pass filter on a Hamamatsu cooled charged coupled device camera. FACS analysis and MTT assay were as mentioned above.

Western blot analysis. Cell lysates were prepared by SDS lysis buffer. Protein concentration was measured using the BCA protein assay kit (Pierce, Rockford, IL, USA). Equal amount of protein was separated by electrophoresis on a $10.5 \%$ SDS polyacrylamide gel. The proteins were electrotransferred from gel to nitrocellulose membrane. The membrane was blocked with 5\% dry milk solution for $30 \mathrm{~min}$, and then incubated with primary antibody for $2 \mathrm{~h}$ at room temperature. After washed, the membrane was incubated with horseradish peroxidase (HRP)-conjugated secondary antibodies. Finally, membrane was detected with the enhanced chemiluminescence (ECL) detection system (Amersham Biosciences Europe, Freiburg, Germany) according to the manufacturer's instructions.

RT-PCR analysis. Total RNAs were isolated from the cells using TRIzol procedure (Invitrogen Life Technologies, Carlsbad, CA, USA). cDNA was synthesized from $4 \mu \mathrm{g}$ of total RNA with SuperScript RT kit (Invitrogen Life Technologies). The reverse transcription PCR exponential phase was determined from 18 to 36 cycles to allow semi-quantitative comparisons among cDNAs developed from identical reactions. Each PCR regime involved an initial denaturation at $94^{\circ} \mathrm{C}$ for $5 \mathrm{~min}$ followed by cycles predetermined for each type of cDNA: 28 cycles for GAPDH and 30 cycles for CAR. Primer sequences were designed as follows: sense primer, 5'-ATA AAG CCA CCA CCG CCA CC-3' and antisense primer, 5'-TGG TCA CAG CTT TCG CAG CC-3' for human GAPDH (internal control); sense primer, 5'-AGC CTT CAG GTG CGA GAT GTT ACG-3' and antisense primer, 5'-TAC GAC AGC AAA AGA TGA TAA GAC-3' for human CAR. The thermal cycle was defined by denaturation at $94^{\circ} \mathrm{C}$ for $5 \mathrm{~min}$, followed by indicated cycles with denaturation at $94^{\circ} \mathrm{C}$ for $30 \mathrm{sec}$, annealing at $60^{\circ} \mathrm{C}$ for $60 \mathrm{sec}$ and extension at $72^{\circ} \mathrm{C}$ for $45 \mathrm{sec}$, and then a final elongation at $72^{\circ} \mathrm{C}$ for $5 \mathrm{~min}$. The PCR products were analyzed on $1 \%$ agarose gels and visualized by ethidium bromide staining.

\section{Results}

Cytotoxicity studies. Cell lines were plated at 7,000 cells/well into 96-well plates. Cisplatin was added the next day, and the plates were assayed after $72 \mathrm{~h}$. The analysis was performed by the MTT assay for the cisplatin-resistant subline cells and its parental cells. The results of MTT assays showed that the $\mathrm{IC}_{50}$ (inhibitory concentration 50\%) of cisplatin to A549 is $1.47 \mu \mathrm{g} / \mathrm{ml}$, and the $\mathrm{IC}_{50}$ of cisplatin to A549/DDP is $15.11 \mu \mathrm{g} / \mathrm{ml}$. Based on these results, we recorded that the resistant factor of A549/DDP was 10.28, and the model of cisplatin-resistant subline was established. 


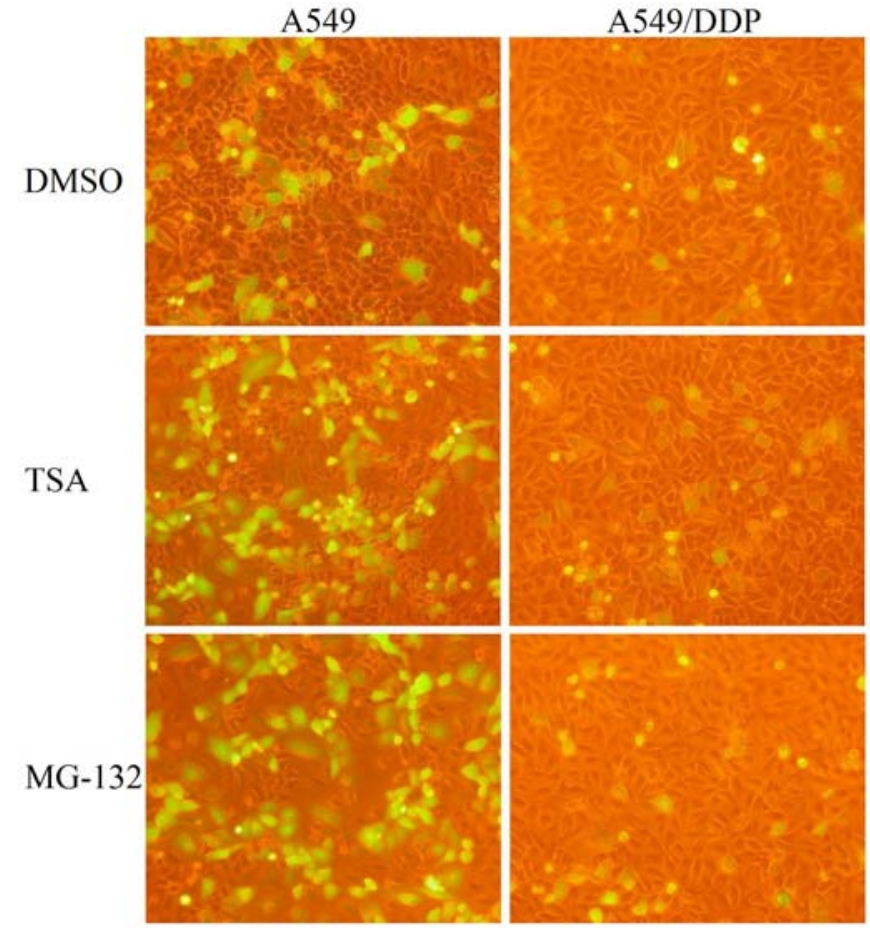

Figure 1. Fluorescence microscope analysis of expression of GFP in adenovirus infected control and TSA or MG-132-treated cells. A549 or A549/DDP cell lines were treated with DMSO, TSA or MG-132 before infection with $2 \mathrm{MOI}$ of rAd.EGFP. The infected cells were grown for $48 \mathrm{~h}$ and virus-mediated gene delivery was determined with fluorescence microscope. Original magnification, $\mathrm{x} 200$.

CAR expressions and $r A d . E G F P$ infection rates of $A 549$ and A549/DDP. A549 and A549/DDP cells were infected with rAd. EGFP at different MOIs, and GFP expression was analyzed in the two cell lines. Compared with A549, A549/DDP showed

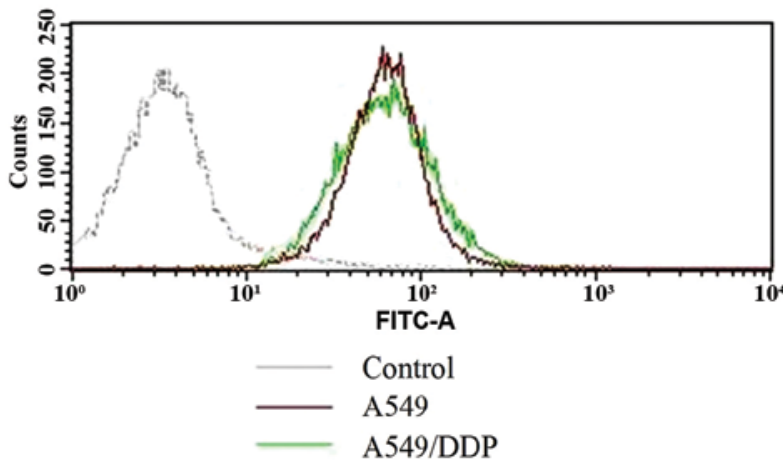

Figure 3. FACS analysis of the CAR expression in A549 and A549/DDP cells.

resistance to adenovirus infection. For example, with $2 \mathrm{MOI}$ of rAd.EGFP, transfer rate of adenovirus was $(29.5 \pm 2.3 \%)$ in A549 and (6.6 $\pm 0.9 \%)$ in A549/DDP cells (Figs. 1 and 2). The difference was significant in statistical analysis $(\mathrm{p}=0.004)$. Nevertheless, FACS analysis of the two cancer cell lines indicated that CAR expression levels of A549 and A549/DDP cells were not different (Fig. 3).

Induction of CAR expression with $M G-132$ and TSA. FACS analysis showed that both A549 and A549/DDP cells were CAR-positive cell lines. Thus, we further studied whether the CAR expression could be affected by drugs, such as MG-132 or TSA. Cytotoxicity studies were performed to determine the minimally cytotoxic concentration of MG-132 or TSA for the two cell lines. For A549 cells, the MG-132 concentration, showing no or minimal cytotoxicity that was selected for these studies were $0.7 \mu \mathrm{mol} / \mathrm{l}$, and the TSA concentration was $30 \mathrm{ng} / \mathrm{ml}$. Whereas, the concentrations of MG-132 for A549/ DDP cells was $0.5 \mu \mathrm{mol} / 1$, and the TSA concentration was also
A549

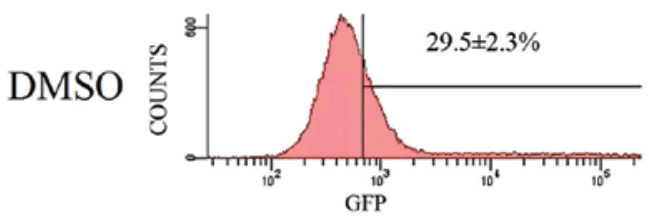

TSA
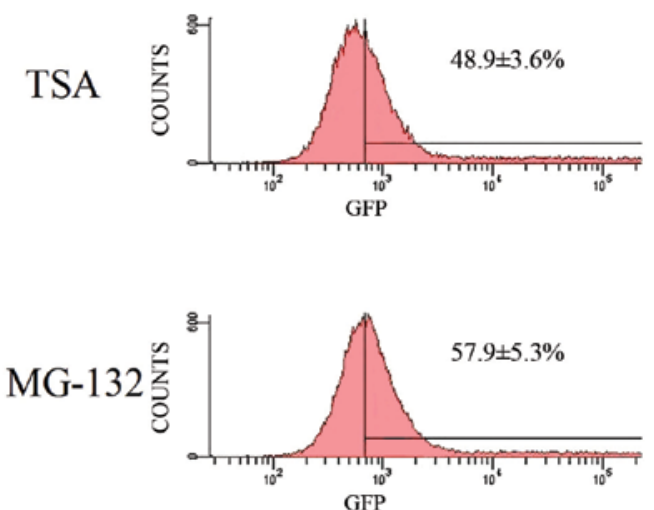

A549/DDP
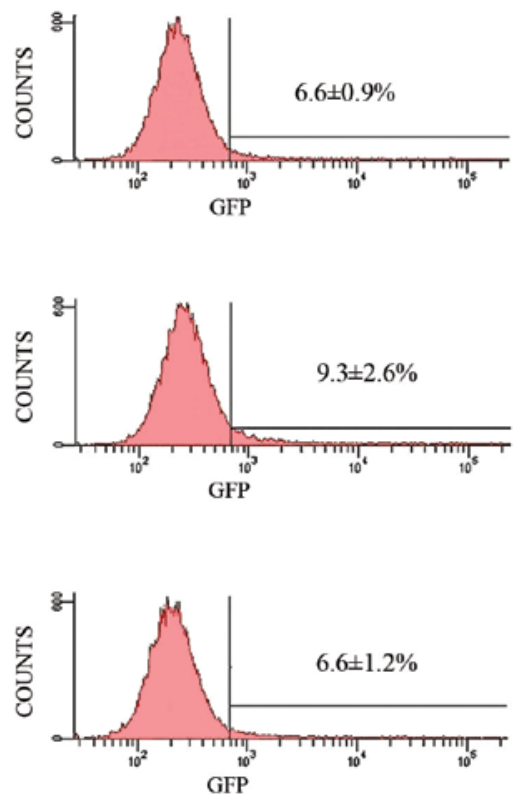

Figure 2. FACS analysis of expression of GFP in adenovirus infected control and TSA or MG-132-treated cells. A549 or A549/DDP cell lines were treated with DMSO, TSA or MG-132 before infection with 2 MOI of rAd.EGFP. The infected cells were grown for $48 \mathrm{~h}$ and virus-mediated gene delivery was determined with FACS. Error bars indicate 1 SD. 

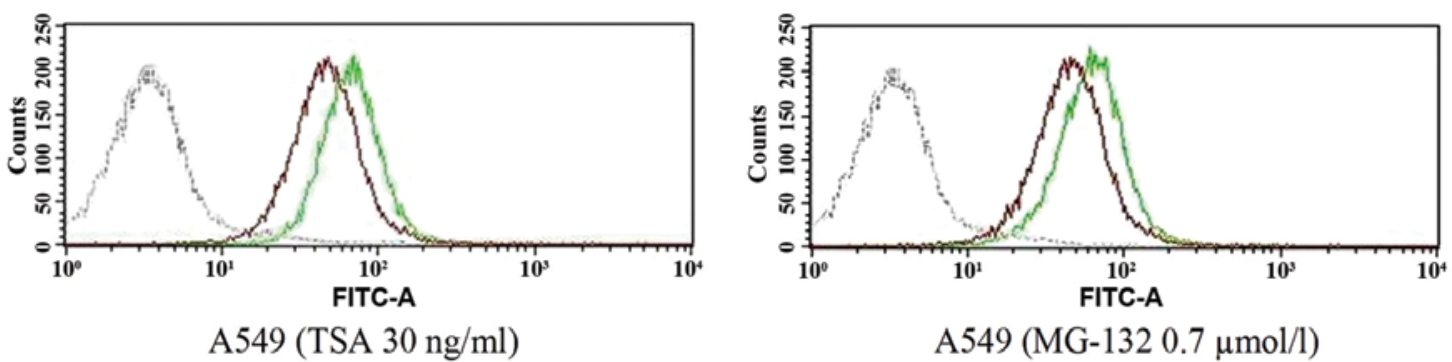

A549 (MG-132 $0.7 \mu \mathrm{mol} / \mathrm{l})$

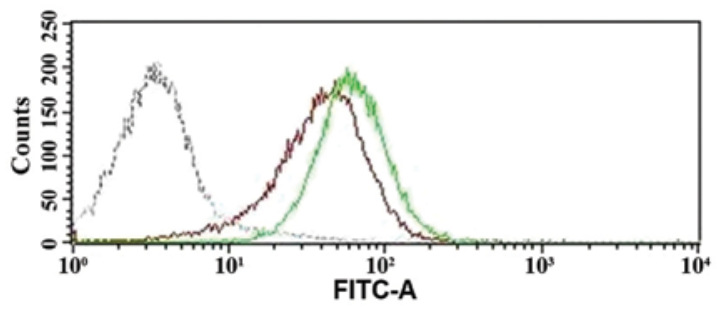

A549/DDP (TSA $30 \mathrm{ng} / \mathrm{ml}$ )

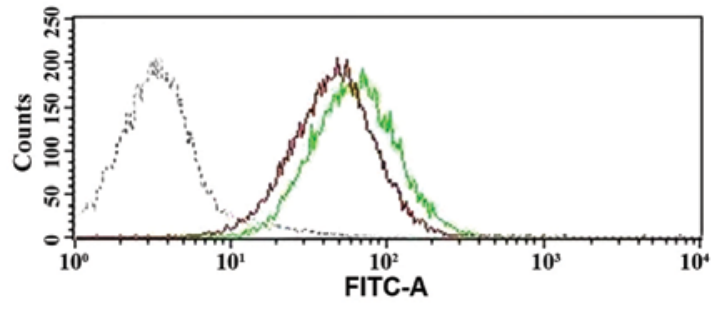

A549/DDP (MG-132 $0.5 \mu \mathrm{mol} / \mathrm{l})$

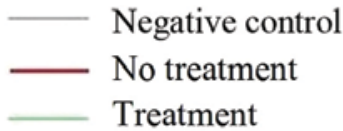

Figure 4. FACS analysis of the CAR expression induced by MG-132 or TSA in A549 and A549/DDP cells.
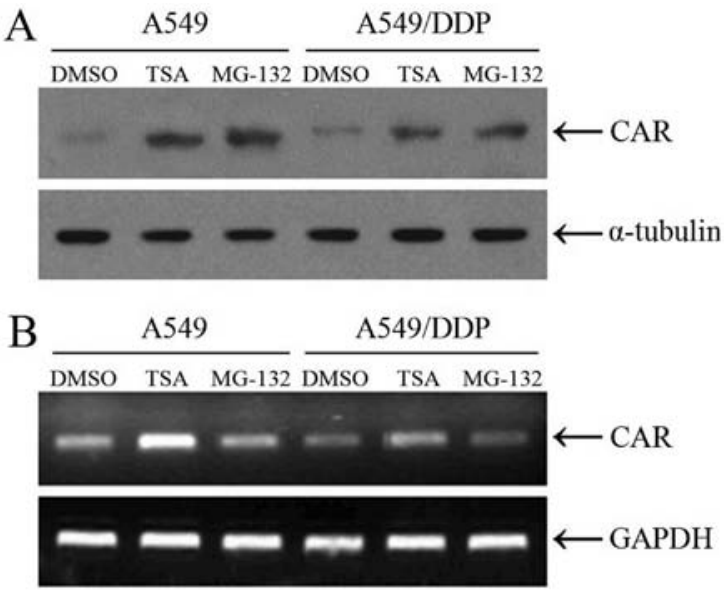

Figure 5. MG-132 and TSA modify CAR expression with different mechanism. (A) Western blotting analysis of CAR protein expression in A549 and A549/DDP cells. (B) RT-PCR of CAR mRNA expression in A549 and A549/ DDP cells.

$30 \mathrm{ng} / \mathrm{ml}$. When A549 cells were incubated with $0.7 \mu \mathrm{mol} / \mathrm{l}$ MG-132 or $30 \mathrm{ng} / \mathrm{ml}$ TSA for $48 \mathrm{~h}$, average CAR density was apparently increased, and the same as A549/DDP cells incubated with MG-132 or TSA (Fig. 4).

We further confirmed the CAR expression levels in A549 and A549/DDP cells with western blotting and RT-PCR analysis. The results showed that TSA rather than MG-132 enhanced the CAR mRNA transcription, which indicated that MG-132 modified the CAR expression with post-transcriptional mechanism and TSA with transcriptional mechanism, consist with the fact that MG-132 is a proteasome inhibitor and TSA a histone deacetylase inhibitor (Fig. 5).
Adenovirus infection affected by MG-132 and TSA. To evaluate the effect of MG-132 or TSA on the adenovirus infectious efficiency, GFP density was compared. Treated with MG-132 or TSA at the indicated concentration for $48 \mathrm{~h}$, A549 or A549/DDP cells were infected with rAd.EGFP at multiplicities of infection (MOI) of $0,0.5,1,2,4$ or 8 , and incubated in normal medium for another $24 \mathrm{~h}$ when analyses was performed. At the indicated time, adenovirus infected cells were photographed under a fluorescent microscope. Then, the infected cells were trypsinized, and further analyzed for GFP expression by flow cytometry.

After MG-132 or TSA treatment, a marked increase in GFP expression of A549 cells occurred with every multiplicity of rAd.EGFP, but the GFP expression was not different in A549/DDP cells after drugs treatments (Fig. 1). For example, with 2 MOI of rAd.EGFP, transfer rate of adenovirus in A549 cells was $(29.5 \pm 2.3 \%)$ in control group $(57.9 \pm 5.3 \%)$ in MG-132 treated group and $(48.9 \pm 3.6 \%)$ in TSA-treated group. In A549/DDP cells, transfer rate of adenovirus was $(6.6 \pm 0.9 \%)$ in control group, $(6.6 \pm 1.2 \%)$ in MG-132-treated group and $(9.3 \pm 2.6 \%)$ in TSA-treated group (Fig. 2).

\section{Discussion}

Previously, various studies have suggested that adenoviral vector-mediated gene therapy is more effective in the drug resistant breast or bladder cancer cell lines compared to the parental cell line, which may partially be explained by the efficiency of adenoviral gene transfer $(18,19)$. In the present study, we employed a human lung cancer cell line and its drug resistant sublines to study adenovirus infection sensibility of the two cell lines. The results shown that rAd.EGFP induced higher GFP gene expression in the parental cell line compared 
to the drug-resistant cell line, indicating greater efficiency of adenovirus-mediated gene transfer in the parental cell lines compared to the drug-resistant line.

Although patients with advanced non-small cell lung cancer (NSCLC) can be effectively treated initially with combination chemotherapy, many patients receiving chemotherapy do not respond, resulting in disease progression. Furthermore, second line chemotherapy provides little benefit to patients who have relapsed after an initial response. Thus, inherent or acquired drug-resistance leads to treatment failure. Much is known concerning the molecular mechanisms by which tumor cells acquire drug-resistance, but the treatment of drug-resistant tumors remains a significant problem. Gene therapy has become an attractive regimen, in addition to conventional therapy, and recombinant adenovirus vectors are widely used in preclinical and clinical gene therapy (4). The p53 gene is abnormal in $40-74 \%$ of NSCLC samples tested (20). Thus, therapeutic approaches involving gene therapy targeting the p53 gene have been explored in preclinical models and clinical trials.

The recombinant adenovirus encoding human p53 tumor suppressor gene (rAd.p53) phase I single agent trials in NSCLC demonstrated effective p53 gene transfer, minimal toxicity and transient injected lesion tumor regression (21). Preclinical studies had previously demonstrated synergistic antitumor effect between adenovirus gene therapy and radiotherapy or chemotherapy, which may lead to enhanced antitumoral activity without increased toxicity $(22,23)$. Combination of p53 gene therapy with radiotherapy has been evaluated in NSCLC patients who were not eligible for chemoradiotherapy or surgery (24). Radiation toxicity was not enhanced by adenoviral vector. Intratumoral injection of rAd. p53 in combination with radiation therapy is well tolerated and demonstrates evidence of tumor regression at the primary injected tumor. Since chemotherapy could not be administered to these high risk patients, systemic control of disease was poor, with over $50 \%$ of patients experiencing metastatic progression within 1 year. The activity and toxicity of rAd.p53 combined with platinum-based chemotherapy were also evaluated in advanced NSCLC. There was no evidence of increased chemotherapy-related toxicity by adenoviral vector, and some evidence of clinical activity could be observed (7). However, in a multicenter phase II study, intratumoral adenoviral p53 gene therapy appears to provide no additional benefit in patients receiving an effective first line chemotherapy for advanced NSCLC (8). One possible explanation for this observation may be the relatively high efficacy of the first line chemotherapy, and gene therapy should be used in a coordinated fashion in the proper clinical context.

Adenovirus can infect cells since it uses the knob domain of the fiber to bind to its cellular receptor, the coxsackie and adenovirus receptor (CAR), and the efficiency of adenoviral gene transfer is critical for adenoviral vector-based gene therapy (10). The efficiency of adenoviral gene transfer to several tumors, including lung cancer, correlates with the expression of CAR, and low levels of CAR in tumors are thought to be one of the reasons for poor adenovirus infection (12-14). We analyzed CAR expressions in the two cell lines, but no significant differences of CAR expression were observed between the A549/DDP and its parental cell line, suggesting that the differences in gene transfer efficiency between the drug resistant cell lines and the parental cell line may be independent of CAR expression. Despite the known importance of CAR for successful transduction of cells, other unknown mechanism of cell virus interaction may also be important. Variable CAR expressions in tumors may interfere with the interpretation of results of clinical trials, but it is too early to determine whether expressions of CAR in tumor cells are appropriate additional criteria for the enrollment of patients in adenovirus gene therapy trials (25).

It is demonstrated that CAR expression could be induced with biological or chemical agents, which would lead to increased adenovirus-mediated transgene expression (15). Histone acetylation inhibitors could restore the gene expression of the tumor-associated genes that have been transcriptionally silenced by promoter associated histone deacetylation, and use of certain histone deacetylase inhibitors, such as FR901228 (26-28), trichostatin A $(29,30)$, CHAP31, FK228 (31,32), SAHA, MS275 and LBH589 (33-35), resulted in an increase in CAR expression in several tumor cell lines, making them more susceptible to adenovirus infectivity. Other agents, such as chemotherapeutics (15), cytokines (36) and inhibitors of the Raf/MEK/ERK pathway (37) were also reported to have the ability to induce CAR expression in some tumor cell lines. Based on the above experiments, we further modified the CAR expression in the two cell lines with proteasome inhibitors MG-132 or histone deacetylase inhibitors TSA, and the results indicated that the CAR expression in both A549 and A549/DDP could be upregulated. In the parental cell lines, upregulated CAR expression with MG-132 or TSA brought about higher GFP gene expression after rAd.EGFP infection, but the upregulated CAR expression in the drugresistant cell lines had no help in GFP gene expression, which also certifies that other unknown mechanism of cell virus interaction beside CAR expression may also be important for the gene transfer efficiency.

Though the CAR expression in A549/DDP cells is no less than its parental cells, the cisplatin-resistant subline shows obvious rejection of the adenovirus infection, which implies that the rejection of adenovirus infection is independent of CAR expression in A549/DDP cells. The mechanism of high efficiency of adenoviral gene transfer in the parental cells is unclear, thus needing further investigation. Inherent or acquired drug-resistance is one of the reasons for antitumor chemotherapy treatment failure. Considering that patients enrolled in adenoviral cancer gene therapy trials usually have received chemotherapy or radiotherapy, the tumor cells in those people usually have multiple drug-resistance (MDR) to a certain degree. After MDR has taken place, the impact of MDR on gene therapy is unknown, and requires investigation.

\section{Acknowledgements}

The present study was supported by the National Natural Science Foundation of China (no. 81272341).

\section{References}

1. Lu S, Yu Y, Chen Z, Ye X, Li Z and Niu X: Maintenance therapy improves survival outcomes in patients with advanced non-small cell lung cancer: A meta-analysis of 14 studies. Lung 193: 805-814, 2015. 
2. Casadio C, Guarize J, Donghi S, Di Tonno C, Fumagalli C, Vacirca D, Dell'Orto P, De Marinis F, Spaggiari L, Viale G, et al: Molecular testing for targeted therapy in advanced non-small cell lung cancer: Suitability of endobronchial ultrasound transbronchial needle aspiration. Am J Clin Pathol 144: 629-634, 2015.

3. Zarogoulidis P, Domvri K, Huang H and Zarogoulidis K: Gene therapy for lung cancer malignant pleural effusion: Current and future nano-biotechnology. Transl Lung Cancer Res 1: 234-237, 2012.

4. Cavazzana-Calvo M, Thrasher A and Mavilio F: The future of gene therapy. Nature 427: 779-781, 2004.

5. Sharma A, Tandon M, Bangari DS and Mittal SK: Adenoviral vector-based strategies for cancer therapy. Curr Drug Ther 4: $117-138,2009$

6. Toloza EM, Morse MA and Lyerly HK: Gene therapy for lung cancer. J Cell Biochem 99: 1-22, 2006.

7. Nemunaitis J, Swisher SG, Timmons T, Connors D, Mack M, Doerksen L, Weill D, Wait J, Lawrence DD, Kemp BL, et al Adenovirus-mediated p53 gene transfer in sequence with cisplatin to tumors of patients with non-small-cell lung cancer. J Clin Oncol 18: 609-622, 2000.

8. Schuler M, Herrmann R, De Greve JL, Stewart AK, Gatzemeier U, Stewart DJ, Laufman L, Gralla R, Kuball J, Buhl R, et al: Adenovirus-mediated wild-type p53 gene transfer in patients receiving chemotherapy for advanced non-smallcell lung cancer: Results of a multicenter phase II study. J Clin Oncol 19: 1750-1758, 2001.

9. Schreiber J, Langhorst H, Jüttner R and Rathjen FG: The IgCAMs CAR, BT-IgSF, and CLMP: Structure, function, and diseases. Adv Neurobiol 8: 21-45, 2014.

10. Kim M, Zinn KR, Barnett BG, Sumerel LA, Krasnykh V, Curiel DT and Douglas JT: The therapeutic efficacy of adenoviral vectors for cancer gene therapy is limited by a low level of primary adenovirus receptors on tumour cells. Eur J Cancer 38: 1917-1926, 2002

11. Ma J, Zhao J, Lu J, Jiang Y, Yang H, Li P, Zhao M, Liu K and Dong Z: Coxsackievirus and adenovirus receptor promotes antitumor activity of oncolytic adenovirus H101 in esophageal cancer. Int J Mol Med 30: 1403-1409, 2012.

12. Li Y, Pong RC, Bergelson JM, Hall MC, Sagalowsky AI, Tseng CP, Wang Z and Hsieh JT: Loss of adenoviral receptor expression in human bladder cancer cells: A potential impact on the efficacy of gene therapy. Cancer Res 59: 325-330, 1999.

13. Pearson AS, Koch PE, Atkinson N, Xiong M, Finberg RW, Roth JA and Fang B: Factors limiting adenovirus-mediated gene transfer into human lung and pancreatic cancer cell lines. Clin Cancer Res 5: 4208-4213, 1999.

14. Qin M, Chen S, Yu T, Escuadro B, Sharma S and Batra RK Coxsackievirus adenovirus receptor expression predicts the efficiency of adenoviral gene transfer into non-small cell lung cancer xenografts. Clin Cancer Res 9: 4992-4999, 2003

15. Hemminki A, Kanerva A, Liu B, Wang M, Alvarez RD, Siegal GP and Curiel DT: Modulation of coxsackie-adenovirus receptor expression for increased adenoviral transgene expression. Cancer Res 63: 847-853, 2003.

16. Zhang NH, Song LB, Wu XJ, Li RP, Zeng MS, Zhu XF, Wan DS, Liu Q, Zeng YX and Zhang XS: Proteasome inhibitor MG-132 modifies coxsackie and adenovirus receptor expression in colon cancer cell line lovo. Cell Cycle 7: 925-933, 2008

17. Lee CH, Kasala D, Na Y, Lee MS, Kim SW, Jeong JH and Yun CO: Enhanced therapeutic efficacy of an adenovirus-PEIbile-acid complex in tumors with low coxsackie and adenovirus receptor expression. Biomaterials 35: 5505-5516, 2014.

18. Shirakawa T, Sasaki R, Gardner TA, Kao C, Zhang ZJ, Sugimura K, Matsuo M, Kamidono $S$ and Gotoh $A$ : Drug-resistant human bladder-cancer cells are more sensitive to adenovirus-mediated wild-type p53 gene therapy compared to drug-sensitive cells. Int J Cancer 94: 282-289, 2001.

19. Ingemarsdotter CK, Tookman LA, Browne A, Pirlo K, Cutts R, Chelela C, Khurrum KF, Leung EY, Dowson S, Webber L, et al: Paclitaxel resistance increases oncolytic adenovirus efficacy via upregulated CAR expression and dysfunctional cell cycle control. Mol Oncol 9: 791-805, 2015.

20. Marchetti A, Buttitta F, Merlo G, Diella F, Pellegrini S, Pepe S, Macchiarini P, Chella A, Angeletti CA, Callahan R, et al: $p 53$ alterations in non-small cell lung cancers correlate with metastatic involvement of hilar and mediastinal lymph nodes. Cancer Res 53: 2846-2851, 1993
21. Swisher SG, Roth JA, Nemunaitis J, Lawrence DD, Kemp BL, Carrasco CH, Connors DG, El-Naggar AK, Fossella F, Glisson BS, et al: Adenovirus-mediated p53 gene transfer in advanced non-small-cell lung cancer. J Natl Cancer Inst 91: 763-771, 1999.

22. Gurnani M, Lipari P, Dell J, Shi B and Nielsen LL: Adenovirusmediated p53 gene therapy has greater efficacy when combined with chemotherapy against human head and neck, ovarian, prostate, and breast cancer. Cancer Chemother Pharmacol 44: 143-151, 1999.

23. Nishizaki M, Meyn RE, Levy LB, Atkinson EN, White RA, Roth JA and Ji L: Synergistic inhibition of human lung cancer cell growth by adenovirus-mediated wild-type p53 gene transfer in combination with docetaxel and radiation therapeutics in vitro and in vivo. Clin Cancer Res 7: 2887-2897, 2001.

24. Swisher SG, Roth JA, Komaki R, Gu J, Lee JJ, Hicks M, Ro JY, Hong WK, Merritt JA, Ahrar K, et al: Induction of p53-regulated genes and tumor regression in lung cancer patients after intratumoral delivery of adenoviral p53 (INGN 201) and radiation therapy. Clin Cancer Res 9: 93-101, 2003.

25. Hasenburg A, Fischer DC, Tong XW, Rojas-Martinez A, Kaufman RH, Ramzy I, Kohlberger P, Orlowska-Volk M, Aguilar-Cordova E and Kieback DG: Adenovirus-mediated thymidine kinase gene therapy for recurrent ovarian cancer: Expression of coxsackie-adenovirus receptor and integrins alphavbeta3 and alphavbeta5. J Soc Gynecol Investig 9: 174-180, 2002.

26. Pong RC, Lai YJ, Chen H, Okegawa T, Frenkel E, Sagalowsky A and Hsieh JT: Epigenetic regulation of coxsackie and adenovirus receptor $(C A R)$ gene promoter in urogenital cancer cells. Cancer Res 63: 8680-8686, 2003

27. Kitazono M, Goldsmith ME, Aikou T, Bates S and Fojo T: Enhanced adenovirus transgene expression in malignant cells treated with the histone deacetylase inhibitor FR901228. Cancer Res 61: 6328-6330, 2001.

28. Watanabe T, Hioki M, Fujiwara T, Nishizaki M, Kagawa S, Taki M, Kishimoto H, Endo Y, Urata Y, Tanaka N, et al: Histone deacetylase inhibitor FR901228 enhances the antitumor effect of telomerase-specific replication-selective adenoviral agent OBP-301 in human lung cancer cells. Exp Cell Res 312: 256-265, 2006.

29. Bieler A, Mantwill K, Dravits T, Bernshausen A, Glockzin G, Köhler-Vargas N, Lage H, Gansbacher B and Holm PS: Novel three-pronged strategy to enhance cancer cell killing in glioblastoma cell lines: Histone deacetylase inhibitor, chemotherapy, and oncolytic adenovirus d1520. Hum Gene Ther 17: 55-70, 2006.

30. El-Zawahry A, Lu P, White SJ and Voelkel-Johnson C: In vitro efficacy of AdTRAIL gene therapy of bladder cancer is enhanced by trichostatin A-mediated restoration of CAR expression and downregulation of cFLIP and Bcl- $\mathrm{X}_{\mathrm{L}}$. Cancer Gene Ther 13: 281-289, 2006.

31. Sasaki Y, Negishi H, Idogawa M, Suzuki H, Mita H, Toyota M, Shinomura Y, Imai K and Tokino T: Histone deacetylase inhibitor FK228 enhances adenovirus-mediated p53 family gene therapy in cancer models. Mol Cancer Ther 7: 779-787, 2008.

32. Earel JK Jr, VanOosten RL and Griffith TS: Histone deacetylase inhibitors modulate the sensitivity of tumor necrosis factorrelated apoptosis-inducing ligand-resistant bladder tumor cells. Cancer Res 66: 499-507, 2006

33. Berghauser Pont LM, Kleijn A, Kloezeman JJ, van den Bossche W, Kaufmann JK, de Vrij J, Leenstra S, Dirven CM and Lamfers ML: The HDAC inhibitors scriptaid and LBH589 combined with the oncolytic virus delta24-RGD exert enhanced anti-tumor efficacy in patient-derived glioblastoma cells. PLoS One 10: e0127058, 2015.

34. Kim DR, Park MY, Lim HJ, Park JS, Cho YJ, Lee SW, Yoon HI, Lee JH, Kim YS and Lee CT: Combination therapy of conditionally replicating adenovirus and histone deacetylase inhibitors. Int J Mol Med 29: 218-224, 2012

35. MacTavish H, Diallo JS, Huang B, Stanford M, Le Boeuf F, De Silva N, Cox J, Simmons JG, Guimond T, Falls T, et al: Enhancement of vaccinia virus based oncolysis with histone deacetylase inhibitors. PLoS One 5: e14462, 2010.

36. Vincent T, Pettersson RF, Crystal RG and Leopold PL: Cytokine-mediated downregulation of coxsackievirus-adenovirus receptor in endothelial cells. J Virol 78: 8047-8058, 2004.

37. Anders M, Christian C, McMahon M, McCormick F and Korn WM: Inhibition of the Raf/MEK/ERK pathway up-regulates expression of the coxsackievirus and adenovirus receptor in cancer cells. Cancer Res 63: 2088-2095, 2003. 